\title{
Ammonia removal from aquaculture wastewater by high flux and high rejection polysulfone/cellulose acetate blend membrane
}

\begin{abstract}
Polysulfone (PSf)/cellulose acetate (CA) blend membranes with diferent compositions (100/0, $90 / 10,85 / 15,80 / 20,75 / 25$ and 70/30) were prepared and characterized for removal of low concentration ammonia (1-10 $\mathrm{mg} / \mathrm{L})$ from aquaculture wastewater. The performance of prepared membranes in terms of pure water fux and ammonia removal percentage was analyzed by diferent experimental variables such as blend membrane compositions, ammonia concentration in feed tank (1, 5 and $10 \mathrm{mg} / \mathrm{L})$ and membrane thickness $(80$ and $100 \mu \mathrm{m})$. The permeability of prepared membranes was examined by pure water fux measurement in feed pressure range of 1-3 bar. The contact angle measurement indicates that the hydrophilicity of PSf/ CA blend membranes is enhanced by increasing the CA concentration in the casting solution. This increment improves the pure water fux of blend membranes. The ammonia removal by PSf/CA $80 / 20(80 \mu \mathrm{m})$ was $79 \%, 99 \%$ and $92 \%$ from feed solutions containing 1 , 5 and $10 \mathrm{mg} / \mathrm{L}$ of ammonia, respectively. The ammonia removal from feed solution containing $1 \mathrm{mg} / \mathrm{L}$ of ammonia is improved from 79 to $95 \%$ (at 2 bar feed pressure) by increasing the thickness of PSf/CA (80/20) membrane from 80 to $100 \mu \mathrm{m}$.
\end{abstract}

Keyword: Blend membrane; Polysulfone; Cellulose acetate; Ammonia removal; Aquaculture wastewater 